\title{
PENERAPAN METODE FINITE STATE MACHINE PADA GAME DREADMAN
}

\author{
Mukhammad Herlambang \\ Program Studi Teknik Informatika S1, Fakultas Teknologi Industri \\ Institut Teknologi Nasional Malang, Jalan Raya Karanglo km 2 Malang, Indonesia \\ Mukhammad.herlambang@gmail.com
}

\begin{abstract}
ABSTRAK
Begitu maraknya pengguna game online multiplayer yang kini sudah tersebar luas dengan berbagai macam genre atau platform, tidak disangka bahwa perkembangan teknologi dan internet berbanding lurus dengan perkembangan industri game. Sehingga Game merupakan salah satu hiburan yang banyak digemari oleh semua kalangan baik anak-anak hingga dewasa. Game dikembangkan berbagai jenis dan salah satunya adalah permainan petualangan. Game Dreadman merupakan Game Adventure. Dimana game ini menceritakan tentang sebuah perjalanan seorang Dreadman yang sedang mencari jimbenya yang telah dicuri oleh zomblis. Zomblis sendiri merupakan pencuri yang telah mengambil jimbe Dreadman.

Dalam game ini penulis menggunakan game engine Unity $3 D$ sebagai tools untuk pembuatan game dengan JDK yang digunakan adalah versi 1.8.0, sedangkan SDK dengan minimum API 4.3 yaitu jelly bean. Dengan menerapkan kecerdasan buatan FSM(Finite State Machine). Dalam penelitian ini FSM diterapkan pada karakter enemy (Louvre) dan bos (Zombli, Brandon, freebird).

Berdasarkan pengujian user yang dilakukan terhadap 10 responden, user menyatakan bahwa sebanyak $80 \%$ tampilan game dreadman adalah cukup. Game dreadman telah diuji pada 5 sistem operasi android (jelly bean, kitkat, lollipop, marshmallow, nougat). Berdasarkan pengujian tersebut didapatkan bahwa game dreadman dapat berjalan dengan lancer dengan minimal RAM yang digunakan 2GB.
\end{abstract}

Kata kunci : game, dreadman, android, finite state machine, Unity3D

\section{PENDAHULUAN}

Game edukasi merupakan Game dengan sistem pembelajaran langsung. Proses pembelajaran yang dilakukan dapat melalui tantangan - tantangan dan pertanyaan-pertanyaan edukatif yang ada dalam permainan Game. Game merupakan salah satu pemanfaatan teknologi yang sangat banyak diminati oleh kalangan tua, muda dan anak yang pada umumnya untuk memperoleh kesenangan dan mengisi waktu kejenuhan semata, namun dengan kemajuan teknologi saat ini berbagai macam Game telah tercipta tidak hanya untuk tujuan kesenangan, namun dapat dimanfaatkan untuk media pembelajaran untuk peningkatan mutu pendidikan. Dari pola yang diterapkan Game edukasi, pemain akan dituntut melakukan proses pembelajaran secara mandiri.

FSM sendiri merupakan metode atau suatu perancangan sistem yang menggambarkan tingkah laku dengan menggunakan 3 hal kejadian keadaan, aksi. dalam Game, Metode FSM menerapkan Berdasarkan sifat tersebut, dapat juga digunakan dalam pengembangan perangkat lunak untuk pengendalian yang bersifat real time maupun reaktif. Cara kerja metode FSM yaitu dimana suatu keadaan akan berpindah apabila telah terpenuhi syaratnya melalui aksi yang telah dilakukan.[1]

Begitu maraknya pengguna Game online multiplayer yang kini sudah tersebar luas dengan berbagai macam genre atau platform, tidak disangka bahwa perkembangan teknologi dan internet berbanding lurus dengan perkembangan industri Game. Di Indonesia banyak sekali anakanak muda hingga dewasa rela utuk menghabiskan waktu berjam-jam untuk bermain Game di smartphonenya. Pada laman newzoo, telah membuat daftar tentang global Games market yang setiap tahun terus diupdate perkembangannya. Dari 25 negara dengan pendapatan tertinggi, Indonesia masuk kedalam peringkat ke-17 dengan total jumlah pengguna internet / Game dengan total pendapatan sekitar \$1milliar dan jumlah pengguna internet sekitar 82 juta.[2]

Pada Game "Dreadman" menggunakan metode FSM (Finite State Machine), dimana metode tersebut berfungsi untuk mengambilan keputusan pada karakter NPC (Non Playable Character) yaitu karakter yang digerakkan oleh kecerdasan buatan yang digunakan untuk mendukung Game tersebut seperti karakter musuh agar gerakan dan aksi dari musuh tanpa melibatkan pengguna Game.[3] 
Dari uraian diatas penulis ingin mengimplementasikan penggunaan metode FSM (Finite State Machine) untuk melakukan pembuatan Game dengan judul "Penerapan Metode Finite State Machine Pada Game Dreadman" yang merupakan Game3D dengan genre Adventure Game, dengan menggunakan Unity sebagai Game engine.

\subsection{Rumusan Masalah}

Rumusan masalah pada pembuatan Game Dreadman ini adalah sebagai berikut:

1. Bagaimana merancang dan mengimplementasikan perilaku agen cerdas menggunakan Finite State Machine pada Non-Playable Character?

2. Bagaimana mengembangkan Game "Dreadman" menggunakan game engine Unity $3 D$ ?

\subsection{Tujuan}

Tujuan dari pembuatan Game Dreadman ini adalah sebagai berikut:

1. Merancang dan mengembangkan game Dreadman dengan Unity $3 D$.

2. Mengimplementasikan Finite State Machine (FSM) sebagai metode untuk menentukan reaksi NPC dalam Game Dreadman.

\subsection{Batasan Masalah}

Agar pembahasan dalam penelitian ini tidak meluas, maka penulis mengambil beberapa batasan masalah, yaitu sebagai berikut :

1. Metode Finite State Machine diimplementasikan pada karakter musuh untuk menyerang karakter utama pemain jika memasuki jarak atau range dari musuh.

2. Game Dreadman Bersifat Single Player Dan $3 D$.

3. Jumlah misi dalam menyelesaikan Game ini akan dibuat sebanyak tiga level.

4. Target pengguna ditujukan untuk usia remaja 12 - 17 tahun.

5. Karakter pada Game Dreadman ini dibuat menggunakan software Blender 2.77.

6. Bahasa pemrograman yang digunakan untuk mengembangkan sistem adalah bahasa $C \#$ pada tools Unity.

\section{TINJAUAN PUSTAKA}

\subsection{Definisi Game}

Game merupakan suatu media yang digunakan untuk menyampaikan suatu tujuan $\mathrm{Di}$ dalam Game terdapat banyak tujuan yang antara lain yaitu edukasi, hiburan ataupun simulasi. Game adalah usaha mengolah diri yang bermanfaat bagi pengembangan dan peningkatan motivasi, kinerja, dan juga prestasi dalam melaksanakan tugas ataupun dalam kepentingan organisasi dengan baik. [7].

Game sendiri terdapat beberapa dampak negatif maupun dampak positif bagi penggunanya. Contoh dampak negatif dari bermain Game ialah dapat merusak mata pengguna jika terlalu lama bermain Game. Dan contoh dampak positif dari bermain Game ialah sebagai penghilang rasa lelah ataupun stres dari bekerja seharian.

\subsection{Dreadman}

Dreadman adalah sebuah nama keren dari pemusik reggae, dreadman bisa di katakan adalah manusia / orang yang rambutnya di gimbal. Maksud dari gimbal ialah helai rambut mirip sebuah tali yang berbentuk anyaman. Rambut gimbal identik dengan orang-orang pecinta music reggae, bob marley, tony q rastafara dll.

\subsection{Finite State Machine}

FSM yaitu sebuah metode perancangan sistem yang bisa menggambarkan sebuah tingkah laku sistem dengan menggunakan tiga hal, Keadaan, kejadian dan aksi. Sistem dapat beralih atau bertransisi menuju state lain jika mendapatkan masukan atau event tertentu, baik yang berasal dari perangkat luar atau komponen dalam sistemnya itu sendiri. Transisi keadaan ini umumnya juga disertai oleh aksi yang dilakukan oleh sistem ketika menanggapi masukan yang terjadi. Aksi yang dilakukan tersebut dapat berupa aksi yang sederhana atau melibatkan rangkaian proses yang relatif komplek. Contoh diagram state sederhana ditunjukkan pada Gambar 2.13.

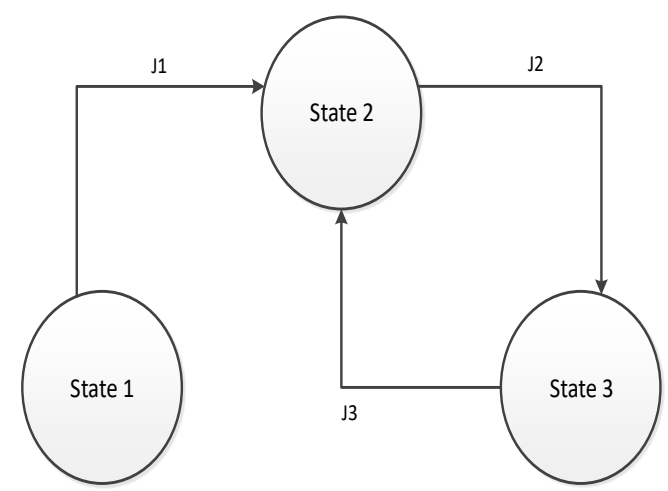

Gambar 2.13 Contoh Diagram State Sederhana

- Simbol Lingkaran : Simbol lingkaran digunakan untuk memberi nama sesuai nama state tersebut. State 1 dan state 2 merupakan lingkaran sementara, dan state 3 adalah lingkaran akhir.

- Simbol Panah : Menunjukkan transisi dari state 1 ke state lain. 
- J1,J2,J3 : kondisi / aksi ketika state dijalankan.

\subsection{Unity 3D}

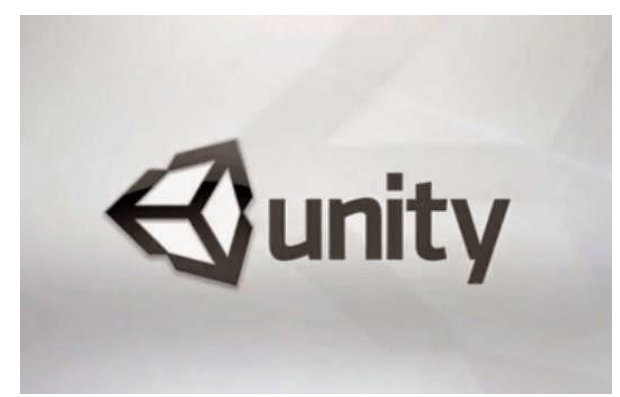

Gambar 2.14 Logo Unity 3D

Unity3D adalah sebuah Game engine yang berbasis cross-platform. game engine unity $3 \mathrm{~d}$ dapat digunakan untuk membuat Game, yang dapat dimainkan pada perangkat komputer Windows atau smartphone. Unity3D juga dapat digunakan untuk membuat web browser Game yang memakai Unity web player plug-in. Fitur scripting yang disediakan, mendukung 2 bahasa pemrograman, JavaScript dan C\#. Dalam Unity, kita tidak dapat melakukan desain atau modeling, dikarenakan Game engine ini dikembangkan bukan untuk mendesain asset-asset untuk Game. Didalam Unity Game Engine terdapat beberapa fitur seperti audio reverb zone, sky box, particle effect dan masih banyak yang lain. Pada Unity juga dapat edit texture dari editor seperti photoshop, illustrator, dll

\subsection{Blender 3D}

\section{Doblender}

Gambar 2.15 Logo Blender 3D

Blender $3 D$ adalah perangkat lunak sumber terbuka grafika komputer $3 D$. Perangkat lunak ini dapat digunakan untuk membuat model 3 dimensi, animasi. Tool Blender sendiri memiliki beberapa fitur, diantaranya tekstur, Gambar bitmap, penulangan, partikel, animasi, video, dan render.[12]

\subsection{Bahasa Pemrograman C\# (C Sharp)}

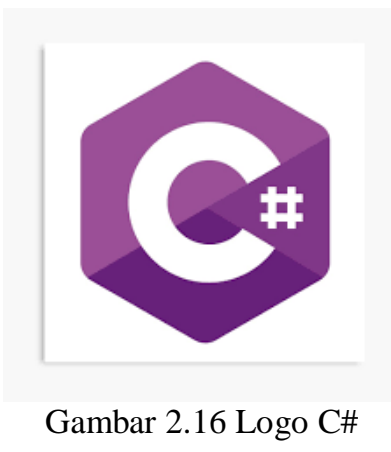

C\# (dibaca: C sharp) merupakan sebuah bahasa pemrograman sederhana yang digunakan untuk tujuan umum. Misalkan digunakan untuk membangun sebuah aplikasi desktop ataupun mobile. Dalam prakteknya Bahasa C\# bergantung pada .NET Framework. .NET Framework digunakan untuk mengcompiler sebuah program yang dibuat dengan Bahasa $\mathrm{C \#}$ atau menjalankan kode yang terdapat pada C\#. Tujuan dibangunnya Bahasa pemrograman $\mathrm{C \#}$ adalah sebagai Bahasa pemrograman utama dalam C\#. Banyak yang mengatakan bahwa C\# dengan Java bersaing, akan tetapi itu tidak. Perlu diketahui sebelumnya Microsoft telah mengembangkan $\mathrm{J}++$ dengan tujuan mencoba membuat Java agar bisa berjalan di platform windows. [13]

\section{METODE PENELITIAN}

\subsection{Flowchart Game Dreadman}

Pada perancangan flowchart game berfungsi untuk mengetahui alur proses dari alur program dimulai dari mulai game hingga selesai. Dapat dilihat seperti gambar 3.1.

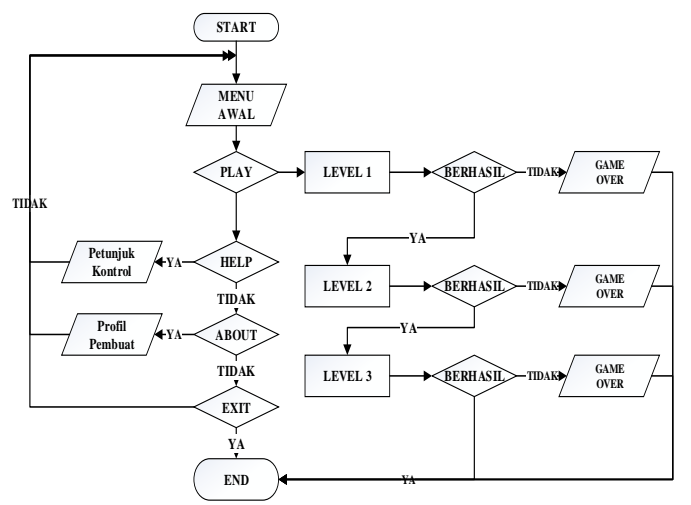

Gambar 3.1 Flowchart Game" Dreadman"

\subsection{Penerapan FSM pada Game}

FSM merupakan sebuah metode yang umum pada sebuah Game untuk menentukan suatu kejadian,aksi, dan kondisi. Perancangan Game "Dreadman" ini menggunakan metode FSM pada Musuh dan Bos. 


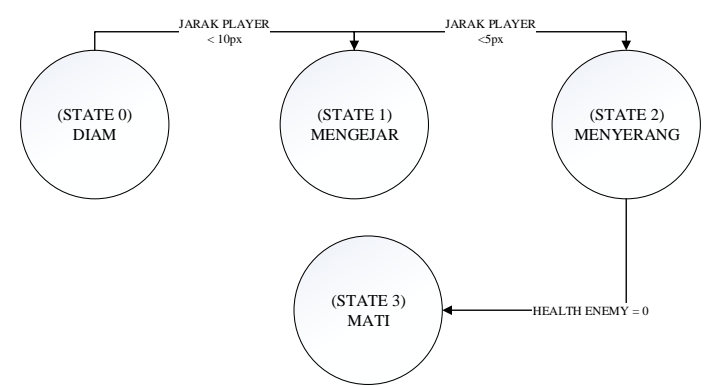

Gambar 3.2 FSM pada enemy

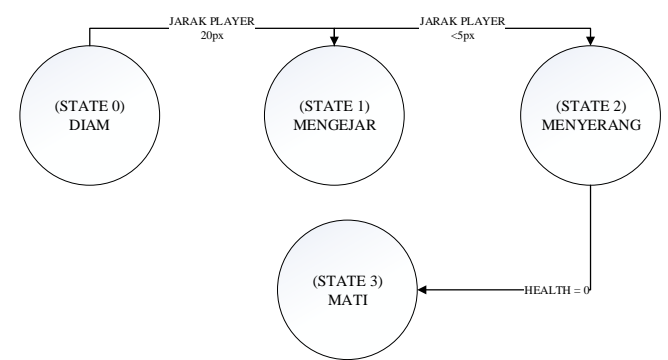

Gambar 3.3 FSM pada Boss

\section{HASIL DAN PEMBAHASAN}

\subsection{Tampilan Menu Utama}

Мепи utama adalah тепи yang akan muncul pertama kali ketika membuka game Dreadman. Pada menu utama terdapat beberapa pilihan yaitu, Play, Help, About dan Quit. Tampilan теnи utama dapat dilihat pada Gambar 4.10 .

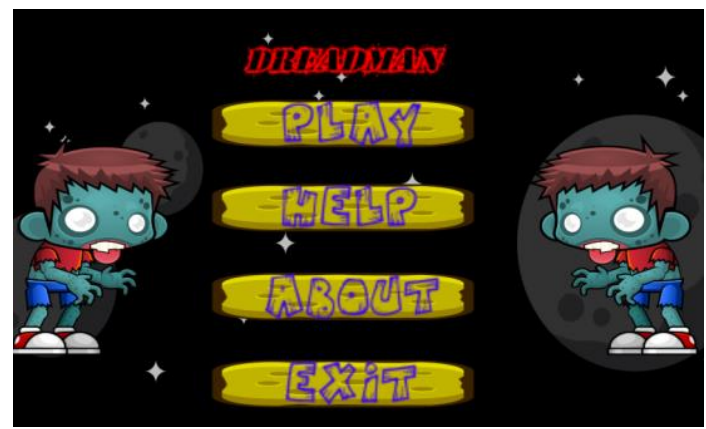

Gambar 4.10 Tampilan Menu Utama

\subsection{Tampilan Menu Help}

Menu help adalah menu yang memuat infromasi mengenai penggunaan kontrol didalam game. Мепи ini akan muncul jika pada menu utama pemain memilih button help. Tampilan menu help dapat dilihat pada Gambar 4.11.

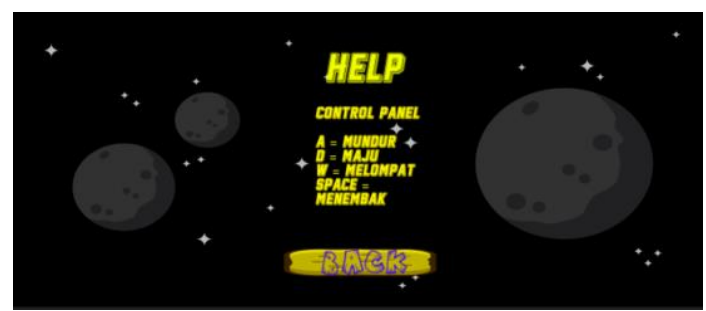

Gambar 4.11 Tampilan Menu Help

\subsection{Tampilan Menu About}

Menu about merupakan menu yang berfungsi untuk menampilkan informasi mengenai pembuat game. Меnи ini akan muncul ketika pemain memilih тепи about pada тепи utama. Tampilan menu about dapat dilihat pada Gambar 4.12.

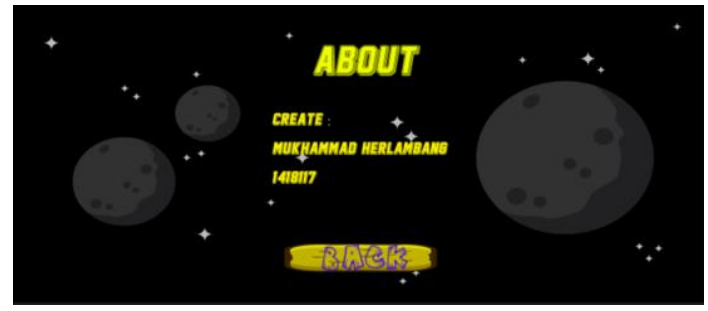

Gambar 4.12 Tampilan Menu About

\subsection{Tampilan Level 1}

Tampilan level 1 adalah tampilan stage level yang nantinya akan dimainkan. Dan pada stage ini player harus berhasil menyelesaikan agar dapat lanjut ke level 2. Tampilan stage level 1 dapat dilihat pada Gambar 4.13

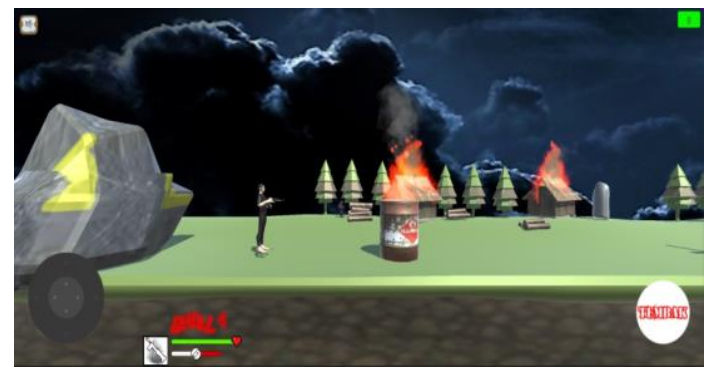

Gambar 4.13 Tampilan Gameplay Level 1

\subsection{Tampilan Level 2}

Tampilan level 2 adalah tampilan stage level yang nantinya akan dimainkan. Dan pada stage ini player harus berhasil menyelesaikan agar dapat lanjut ke level 3. Tampilan stage level 1 dapat dilihat pada Gambar 4.14 


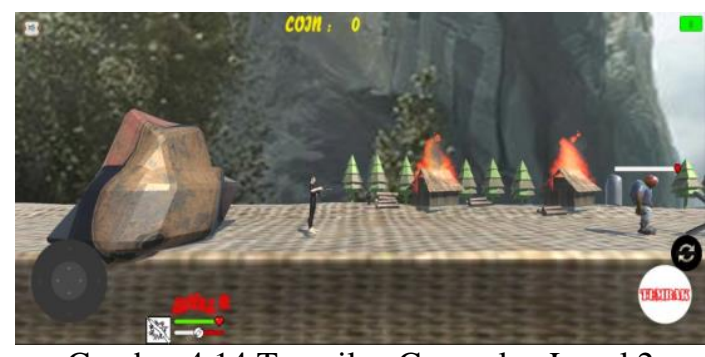

Gambar 4.14 Tampilan Gameplay Level 2

\subsection{Tampilan Level 3}

Tampilan level 3 adalah tampilan stage level yang nantinya akan dimainkan. Dan pada stage ini player berhasil maka game akan selesai. Tampilan stage level 3 dapat dilihat pada Gambar 4.15

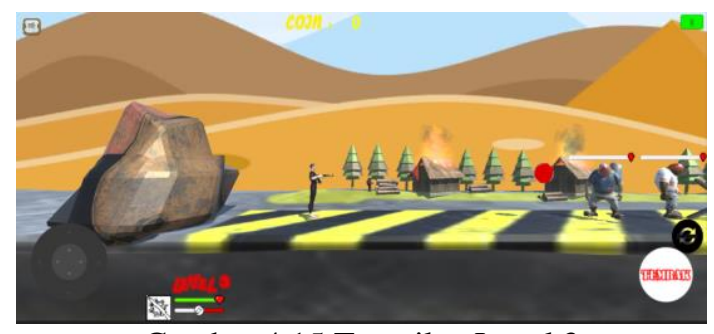

Gambar 4.15 Tampilan Level 3

\subsection{Pengujian AI}

Pengujian FSM adalah pengujian mengenai fungsi yang ada pada NPC dalam game. Hasil dari pengujian Finite State Machine pada musuh dapat dilihat pada Tabel 4.2.

Tabel 4.2 Pengujian AI

\begin{tabular}{|c|c|c|c|c|c|}
\hline No & Karakter & State & Condition & Action & Hasil \\
\hline \multirow{4}{*}{1} & \multirow{4}{*}{ Louvre } & State 0 & Jarak $>5 \mathrm{px}$ & Diam & Sesuai \\
\hline & & State 1 & Jarak 5px & Mengejar & Sesuai \\
\hline & & State 2 & Jarak $<5 p x$ & Menyerang & Tidak Sesuai \\
\hline & & State 3 / any state & $\mathrm{HP}<=0$ & Mati & Sesuai \\
\hline \multirow{4}{*}{2} & \multirow{4}{*}{ Zomblies } & State 0 & Jarak > 3px & Diam & Sesuai \\
\hline & & State 1 & Jarak $<=3 p x$ & Mengejar & Sesuai \\
\hline & & State 2 & Jarak $<3 \mathrm{px}$ & Menyerang & Tidak Sesuai \\
\hline & & State 3 / any state & $\mathrm{HP}<=0$ & Mati & Sesuai \\
\hline \multirow{4}{*}{3} & \multirow{4}{*}{ Brandon } & State 0 & Jarak > 6px & Diam & Sesuai \\
\hline & & State 1 & Jarak $<=6 \mathrm{px}$ & Mengejar & Sesuai \\
\hline & & State 2 & Jarak < 6px & Menyerang & Tidak Sesuai \\
\hline & & State 3 / any state & $\mathrm{HP}<=0$ & Mati & Sesuai \\
\hline \multirow{4}{*}{4} & \multirow{4}{*}{ FreeBird } & State 0 & Jarak > 12px & Diam & Sesuai \\
\hline & & State 1 & Jarak $<=12 \mathrm{px}$ & Mengejar & Sesuai \\
\hline & & State 2 & Jarak < 12px & Menyerang & Tidak Sesuai \\
\hline & & State 3 / any state & $\mathrm{HP}<=0$ & Mati & Sesuai \\
\hline 5 & Lebah & State 0 & Jarak >20px & Patroli & Sesuai \\
\hline 6 & Dino & State 0 & Jarak >20px & Patroli & Sesuai \\
\hline 7 & Listrik & State 0 & Jarak 0px & Diam & Sesuai \\
\hline
\end{tabular}

Dari hasil pengujian pada Tabel 4.2 secara keseluruhan bejalan dengan baik dan sesuai tetapi mempunyai kendala pada karakter enemy dan bos adalah pada pengujian state 2, yaitu state menyerang.

\subsection{Pengujian Control Player}

Pengujian control pada player berfungsi untuk mengetahui apakah semua button yang terdapat pada Keyboard yang digunakan untuk bermain dalam game berfungsi sesuai dengan yang diharapkan atau belum sesuai. Pengujian

Tabel 4.2 Pengujian Control Controll player dapat dilihat pada tabel 4.2

\begin{tabular}{|c|c|c|c|c|c|}
\hline No & Control & Fungsi & Hasil & Berhasil & Gagal \\
\hline 1 & $\rightarrow$ & $\begin{array}{c}\text { Berjalan } \\
\text { Maju }\end{array}$ & $\begin{array}{c}\text { Player } \\
\text { Bergerak } \\
\text { Ke depan }\end{array}$ & $\checkmark$ & - \\
\hline 2 & $\leftarrow$ & $\begin{array}{c}\text { Berjalan } \\
\text { Mundur }\end{array}$ & $\begin{array}{c}\text { Player } \\
\text { Bergerak } \\
\text { Ke } \\
\text { belakang }\end{array}$ & $\checkmark$ & - \\
\hline 4 & $\begin{array}{c}\text { Button } \\
\text { Tembak }\end{array}$ & Menembak & $\begin{array}{c}\text { Player } \\
\text { Menembak }\end{array}$ & $\checkmark$ & - \\
\hline
\end{tabular}




\subsection{Pengujian User}

Pengujian user dilakukan untuk mengetahui seberapa persen aplikasi ini sudah dibuat dengan baik atau belum. Pada pengujian user dilakukan pada 10 orang yang ada di daerah pasuruan. Berikut pengujian user ditunjukkan pada tabel 4.3.

Tabel 4.3 Tabel Pengujian User

\begin{tabular}{|c|c|c|c|c|}
\hline \multirow[t]{2}{*}{ No } & \multirow{2}{*}{ Petanyaan } & \multicolumn{3}{|c|}{$\begin{array}{l}\text { Penilaian } \\
\text { (orang) }\end{array}$} \\
\hline & & $\mathbf{K}$ & $\mathbf{C}$ & B \\
\hline 1 & $\begin{array}{l}\text { Apakah tampilan pada game } \\
\text { Dreadman sudah menarik } \\
\text { pengguna? }\end{array}$ & 2 & 8 & - \\
\hline 2 & $\begin{array}{l}\text { Apakah game Dreadman } \\
\text { mudah dipahami oleh } \text { user? }\end{array}$ & 2 & 4 & 4 \\
\hline 3 & $\begin{array}{l}\text { Apakah Control pada Player } \\
\text { sudah dapat dijalankan atau } \\
\text { sudah sesuai? }\end{array}$ & 1 & 4 & 5 \\
\hline 4 & $\begin{array}{l}\text { Apakah enemy mempunyai } \\
\text { kecerdasan buatan untuk } \\
\text { mengejar pada saat player } \\
\text { mendekat dengan jarak yang } \\
\text { ditentukan pada saat } \\
\text { digunakan dengan } \\
\text { penggunaan } \text { user? }\end{array}$ & 1 & 5 & 4 \\
\hline 5 & $\begin{array}{l}\text { Apakah enemy mempunyai } \\
\text { kecerdasan buatan untuk } \\
\text { Menyerang pada saat player } \\
\text { mendekat dengan jarak yang } \\
\text { ditentukan pada saat diguna- } \\
\text { kan dengan penggunaan } \text { user? }\end{array}$ & 2 & 4 & 4 \\
\hline & Jumlah & $\stackrel{\infty}{a}$ & 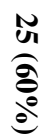 & 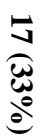 \\
\hline
\end{tabular}

Berdasarkan Tabel 4.5, didapatkan hasil pengujian user sebagai berikut, kurang Sebesar 7\%, Cukup Sebesar 60\%, dan Baik Sebesar 33\%. Oleh karena itu hasil pengujian terhadap 10 orang responden cenderung menilai game dengan nilai cukup, yaitu dengan nilai prosentase $60 \%$.

\subsection{Pengujian Performa}

Pada pengujian performa ini game akan dicoba dijalankan / dimainkan pada beberapa operasi sistem. Hasil pengujian pada OS dapat dilihat pada tabel 4.4

Tabel 4.4 Tabel Pengujian Performa

\begin{tabular}{|c|l|c|c|c|c|}
\hline \multirow{2}{*}{ No } & \multirow{2}{*}{\begin{tabular}{c}
\multirow{2}{*}{$\begin{array}{c}\text { Operating } \\
\text { System }(\text { OS })\end{array}$} \\
\cline { 3 - 5 }
\end{tabular}} & RAM & $\begin{array}{c}\text { Tampilan } \\
\text { cape }\end{array}$ & $\begin{array}{c}\text { Por } \\
\text { trait }\end{array}$ & Hasil \\
\hline 1. & $\begin{array}{l}6.0 \\
\text { (Marshmallow) }\end{array}$ & $2 \mathrm{~GB}$ & $\sqrt{ }$ & $\sqrt{ }$ & Lancar \\
\hline 2. & 7.1 .1 (Nougat) & $3 \mathrm{~GB}$ & $\sqrt{ }$ & $\sqrt{ }$ & Lancar \\
\hline 3. & 5.1 (Lollipop) & $2 \mathrm{~GB}$ & $\sqrt{ }$ & $\sqrt{ }$ & Lancar \\
\hline 4. & $\begin{array}{l}4.1 \\
\text { (Jelly Bean) }\end{array}$ & $1 \mathrm{~GB}$ & $\sqrt{ }$ & $\sqrt{ }$ & $\begin{array}{c}\text { Tidak } \\
\text { Lancar }\end{array}$ \\
\hline 5. & 8.0 (Oreo) & $2 \mathrm{~GB}$ & $\sqrt{ }$ & $\sqrt{ }$ & Lancar \\
\hline
\end{tabular}

Keterangan :

$\sqrt{ }$ : Bisa tampil sesuai dengan pada saat pembuatan dan tidak ada tampilan yang terpotong

$\checkmark$ : Bisa Tampilan game, tetapi ada tampilan yang terpotong

Lancar : Game dikatakan lancar yaitu pada saat memainkan game tidak ada tersendatnya

Tidak Lancar : Game dikatakan tidak lancar apabila mulai dari scene level 1 sampai level 3 Game dijalankan agak tersendatsendat atau pada saat dimainkan game agak lama.

\subsection{Pengujian Fungsional}

Pengujian fungsional adalah pengujian mengenai proses fungsional yangada dalam Game. Hasil dari pengujian dapat dilihat pada Tabel 4.5

Tabel 4.5 Pengujian Fungsional

\begin{tabular}{|c|l|c|c|c|c|c|}
\hline \multirow{2}{*}{ No } & \multirow{2}{*}{ Item uji } & \multicolumn{5}{|c|}{ Operating System } \\
\cline { 3 - 7 } & A & B & C & D & E \\
\hline 1 & Menu Utama & $\sqrt{ }$ & $\sqrt{ }$ & $\sqrt{ }$ & $\sqrt{ }$ & $\sqrt{ }$ \\
\hline 2 & Button Play & $\sqrt{ }$ & $\sqrt{ }$ & $\sqrt{ }$ & $\sqrt{ }$ & $\sqrt{ }$ \\
\hline 3 & Buttom Help & $\sqrt{ }$ & $\sqrt{ }$ & $\sqrt{ }$ & $\sqrt{ }$ & $\sqrt{ }$ \\
\hline 4 & $\begin{array}{l}\text { Button } \\
\text { About }\end{array}$ & $\sqrt{ }$ & $\sqrt{ }$ & $\sqrt{ }$ & $\sqrt{ }$ & $\sqrt{ }$ \\
\hline 5 & Button Exit & $\sqrt{ }$ & $\sqrt{ }$ & $\sqrt{ }$ & $\sqrt{ }$ & $\sqrt{ }$ \\
\hline 6 & Level 1 & $\sqrt{ }$ & $\sqrt{ }$ & $\sqrt{ }$ & $\sqrt{ }$ & $\sqrt{ }$ \\
\hline 7 & Level 2 & $\sqrt{ }$ & $\sqrt{ }$ & $\sqrt{ }$ & $\sqrt{ }$ & $\sqrt{ }$ \\
\hline 8 & Level 3 & $\sqrt{ }$ & $\sqrt{ }$ & $\sqrt{ }$ & $\sqrt{ }$ & $\sqrt{ }$ \\
\hline 9 & $\begin{array}{l}\text { Health } \\
\text { Player }\end{array}$ & $\sqrt{ }$ & $\sqrt{ }$ & $\sqrt{ }$ & $\sqrt{ }$ & $\sqrt{ }$ \\
\hline 10 & $\begin{array}{l}\text { Health } \\
\text { enemy }\end{array}$ & $\sqrt{ }$ & $\sqrt{ }$ & $\sqrt{ }$ & $\sqrt{ }$ & $\sqrt{ }$ \\
\hline 11 & $\begin{array}{l}\text { Sound Menu } \\
\text { Utama }\end{array}$ & $\sqrt{ }$ & $\sqrt{ }$ & $\sqrt{ }$ & $\sqrt{ }$ & $\sqrt{ }$ \\
\hline 12 & $\begin{array}{l}\text { Sound Next } \\
\text { Level }\end{array}$ & $\sqrt{ }$ & $\sqrt{ }$ & $\sqrt{ }$ & $\sqrt{ }$ & $\sqrt{ }$ \\
\hline 13 & $\begin{array}{l}\text { Sound } \\
\text { Senjata }\end{array}$ & $\sqrt{ }$ & $\sqrt{ }$ & $\sqrt{ }$ & $\sqrt{ }$ & $\sqrt{ }$ \\
\hline 14 & $\begin{array}{l}\text { Sound } \\
\text { Player Mati }\end{array}$ & $\sqrt{ }$ & $\sqrt{ }$ & $\sqrt{ }$ & $\sqrt{ }$ & $\sqrt{ }$ \\
\hline 15 & $\begin{array}{l}\text { Sound } \\
\text { Enemy }\end{array}$ & $\sqrt{ }$ & $\sqrt{ }$ & $\sqrt{ }$ & $\sqrt{ }$ & $\sqrt{ }$ \\
\hline
\end{tabular}

\section{KESIMPULAN DAN SARAN}

\subsection{Kesimpulan}

Berdasarkan hasil dan pembahasan pada game Dreadman maka dapat diambil beberapa kesimpulan sebagai berikut :

1. Hasil dari pengujian kecerdasan buatan yang diterapkan pada enemy telah berjalan dengan baik dan sesuai.

2. Hasil dari pengujian Kontrol pada player berfungsi dengan baik dan sesuai

3. Hasil dari pengujian fungsional yang dilakukan 5 Android System yang berbeda yaitu OS Jelly bean, Lollipop, Marshmallow, 
Nougat, Oreo. Dan telah berjalan dengan baik dan sesuai.

4. Berdasarkan pengujian user yang dilakukan terhadap 10 responden, user menyatakan bahwa sebanyak $80 \%$ tampilan pada game dreadman adalah cukup.

5. Game Dreadman dikatakan tidak lancar ketika RAM kurang dari 2GB dan lancar dapat dimainkan dengan RAM minimal 2 GB, Versi Android Minimal 4.4 (KitKat). Untuk JDK yang digunakan pada game Dreadman adalah versi 1.8.0, sedangkan SDK dengan minimum API 4.3 yaitu jelly bean Dan untuk tampilan layarnya digunakan landscape dikarenakan gambar tidak terpotong. Game dikatakan tidak lancar apabila mulai dari scene level 1 sampai level 3 game dijalankan agak tersendat-sendat atau pada saat dimainkan game agak lama. Dan untuk yang lancar yaitu pada saat memainkan game tidak ada tersendatnya

\subsection{Saran}

Adapun saran yang dapat diberikan sebagai acuan terhadap pengembangan selanjutnya dari game Dreadman:

1. Menyeimbangkan damage dan jumlah $h p$ player dengan musuh.

2. Menambah karakter enemy dan player.

3. Dapat mengembangkan lagi game "Dreadman" dengan menambahkan level, save game, score game.

\section{DAFTAR PUSTAKA}

[1] Azhar, Nurul, Game pengenalan namanama hewan berbasis role playing Game menggunakan Ruby Game Scripting System, Surabaya, 2011.

[2] Afifah, L. 2019. 25 Negara dengan Gamers terbanyak sedunia. http://idntimes.com/tech/Gamers/amp/lutfia -afifah/25-negara-dengan-jumlah-penggilaGame-terbanyak-di-dunia-c1c2. [Diakses 25 Juni 2019]

[3] Adi Wijaya, Surya., Susi Juniastuti, Supeno Mardi SN, dan Moch. Hariadi. 2009. Desain Fuzzy State Machine Untuk Menghasilkan Variasi Respon NPC (NonPlayable Character) Pada Sebuah Game. Program Studi MMT-ITS.

[4] Rostianingsih, Budhi, dan Wijaya . 2013. GAME SIMULASI FINITE STATE
MACHINE UNTUK PERTANIAN DAN PETERNAKAN

[5] Rachmah, 2008. IMPLEMENTASI ALGORITMA GREEDY PADA PERMAINAN OTHELLO. http://docplayer.info/47736207-

Implementasi-algoritma-greedy-padapermainan-othello.html

[6] Irawan Joseph Dedy, Prasetio Sonny, Wibowo Suryo Adi, Pranoto Yosep Agus. 2015. PELATIHAN PEMBUATAN GAME MENGGUNAKAN GREENFOOT. Prodi Teknik Informatika, Fakultas Teknologi Industri, Institut Teknologi Nasional Malang

[7] Fauziyah Dan Amugraha, Agustian 2018. Game Edukasi Berbasis Kinect untuk Anak Berkebutuhkan Khusus (Autis) dengan Metode Finite State Machine.

[8] Fajar, M., Ramadhan, R., \& Ningrum, I. P. (2015). Membangun aplikasi Game" dua satu (21)" berbasis Android menggunakan metode depth first search, 1(2), 63-68.

[9] Haryanto, H. (2010). Agen Cerdas Kompetitif Berbasis Finite State Machine Dalam Game Pembelajaran Untuk Anak, 53-61.

[10] Marzian, Fadel., Mukti Qamal. (2017) Game RPG "The Royal Sword" Berbasis Desktop Dengan Menggunakan Metode Finite State Machine (FSM). Teknik Informatika Universitas Malikussaleh Lhokseumawe

[11] Tjahjono, Harvey. Liliana. Gunadi, Kartika. (2015). Pembuatan Game Cerita Rakyat Dengan Bentuk Adventure Game.Vol 3, No 2 (2015).

[12] Blender Org. About Blender 3D. (Online) Tersedia : https://www.blender.org/about/, [Diakses 24 Juni 2019]

[13] Filus, Teo. 2017. "Pengenalan Bahasa Pemrograman C\#”, (Online) Tersedia : http://www.codepolitan.com/pengenalanbahasa-pemrograman-c-587effa1cb95b.

[14] Komputer, Wahana. 2012. Langkah Praktis Membangun Aplikasi Sederhana Platform Android. Jakarta: PT. Elex Media Komputindo.

[15] https://salamadian.com/simbol-simbolflowchart/ [Diakses 24 Juli 2019] [Diakses 24 Juli 2019] 